\title{
Research on Incentive Mode of Post-90s Employees in SMEs
}

\author{
Youjun $\mathrm{Wu}^{\mathrm{a},}{ }^{*}$, Beiling $\mathrm{Li}^{\mathrm{b}}$, Lijun Yin ${ }^{\mathrm{c}}$, Xinyi Zhang ${ }^{\mathrm{d}}$ and $\mathrm{Yu} \mathrm{Liu}^{\mathrm{e}}$ \\ Evergrande College of Management, Wuhan university of science and technology, Wuhan, China \\ Email:1656152185@qq.com, ${ }^{b} 1533218406 @ q q . c o m,{ }^{c} 1603778098 @ q q . c o m,{ }^{d} 895908825 @ q q . c o m$, \\ 1900756327@qq.com \\ *Corresponding author. Email: 656152185@qq.com
}

\begin{abstract}
At present, the post-90s employees have become the backbone of all walks of life, and the post-95s are gradually entering the workplace. Their entry has brought great challenges to the management and incentive of enterprises. Reform and opening up, economic globalization, popularization of higher education, informationization .etc have given post-90s employees new features. They pay more attention to their own development space, and are more eager for innovation and challenges, which exposes their obvious shortcomings, such as high employee turnover rate, weak stress resistance and weak awareness of rules. How to manage post-90s employees has become a serious problem for enterprises to rethink seriously, and the incentive for the post-90s has become an essential part.This paper mainly adopts the questionnaire survey, literature review and interview method to analyze and summarize the personality characteristics of the post-90s employees and the existing problems of incentive mode in small and medium-sized enterprise, so as to construct a new professional incentive method for post-90s employees, achieving a win-win situation in enterprises, employees and performance.
\end{abstract}

Keywords: Post-90s employees, Incentives, Small and medium-sized enterprise (SME).

\section{INTRODUCTION}

Since entering the 21 st century, the changes brought about by the Internet have made people have a deep understanding both in life and in spirit. The post-90s who grew up in this era have undergone earth-shaking changes from various aspects such as thinking and actions compared to post-70s and post-80s. As post-95 employees continue to enter the workplace, post- 90 employees have also become the backbone of the workplace. They have become an important part of the enterprise, occupying an important position in enterprise management activities and becoming an important management object. They have different values and pursuits with the post-70s and post-80s employees, so the management methods for them also need to be adjusted. How to make the post-90s contribute their greatest strength in the work and how to make the post-90s achieve self-worth in the work have become the issues that managers need to focus on.

Small and medium-sized enterprises play an extremely important role in the process of China's economic development, and they also occupy an important position in China's economy and society, which are the main force in China's economic development. It is well known that the orderly development of SMEs plays a vital role in building a harmonious and beautiful economy and society as well as building a sustainable development country in China. However, because most enterprises are still in the early stage of start-up or development, their own enterprise capacity are insufficient and their incentive methods are imperfect. The demand analysis for the post-90s employees is not comprehensive, resulting in a high turnover rate of the post-90s employees. Therefore, to build a reasonable and perfect incentive mode for post-90s is a major problem that SMEs need to solve.

\section{CURRENT SITUATION AND PROBLEMS OF POST-90S EMPLOYEE INCENTIVES IN SMES}

\subsection{Basic Information of Questionnaire Survey}

In order to increase the authenticity and credibility of the research, this paper places the research on the 
incentive mode of post-90s employees in the whole SMEs to investigate. The survey objects are mainly the post-90s employees, so the analysis results are more objective and realistic. The questionnaire survey was conducted by anonymous and random sampling, and the respondents included this type of work, so that we can understand employees' incentive needs more comprehensively. A total of 72 questionnaires were collected, of which 61 were valid.

\subsection{Analysis of Survey Results}

\subsubsection{Analysis on the General Situation of Post-90s Employees' Work Characteristics}

According to the results, the prominent characteristics of the post-90s employees in their work include: having clear and specific goals, preferring working in the form of a team and acting flexibly. The specific data are shown in Figure 1. But post-90s employees have obvious shortcomings such as lack of creativity, easy to ignore details and not expressing their opinions. The specific date are shown in Figure 2.

\subsubsection{Analysis of the Overall Situation of Post-90s Employees'Incentive Satisfaction}

According to the analysis of the results, the post-90s employees of small and medium-sized enterprises have a low degree of satisfaction with the current salary system and welfare treatment, but they are more satisfied with corporate culture and communication with their superiors, as shown in Table 1.

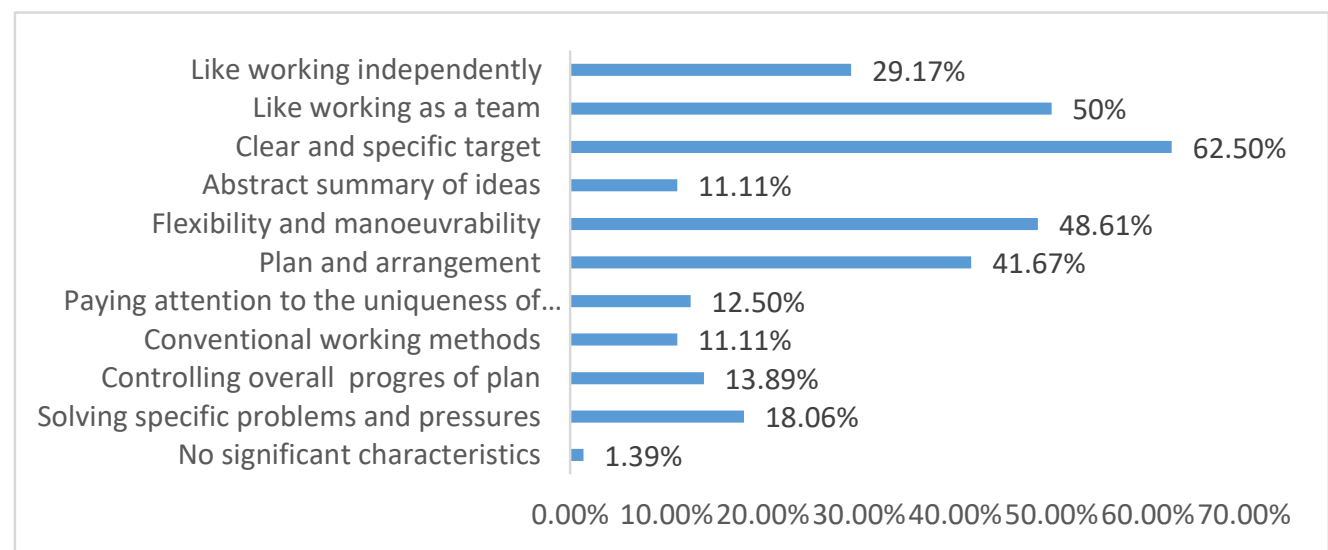

Figure 1. Analysis on the Outstanding Features of Post-90s Workers

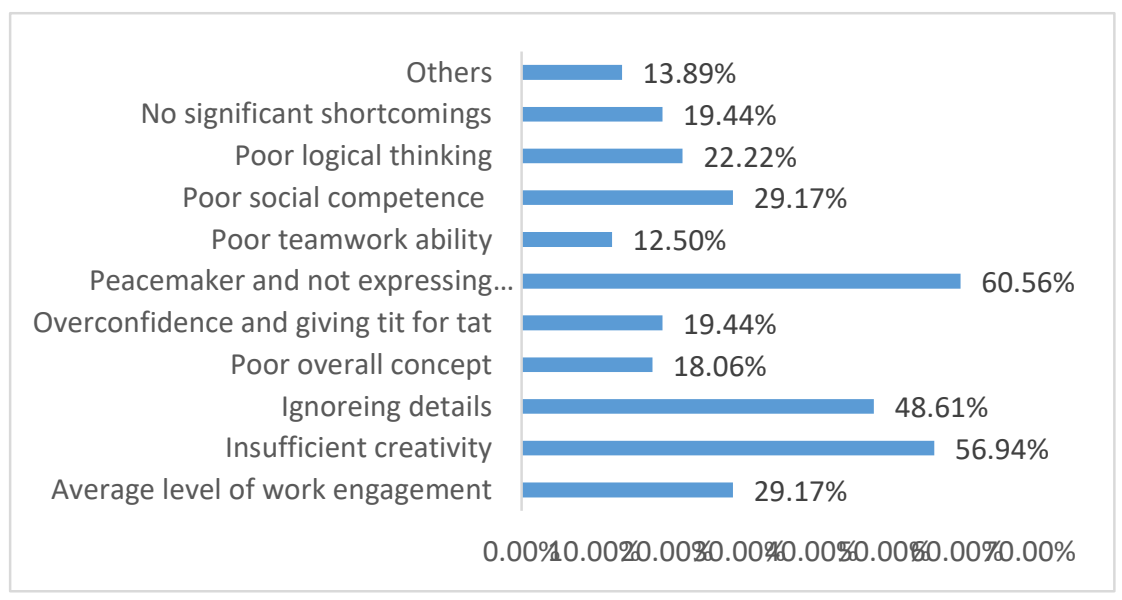

Figure 2. Analysis of obvious shortcomings of post-90s employees in the work 
Table 1. Analysis of post-90s employee incentive satisfaction

\begin{tabular}{|c|c|c|c|c|c|}
\hline Question\Options & $\begin{array}{c}\text { Very } \\
\text { dissatisfied }\end{array}$ & Dissatisfied & Common & Satisfied & Very Satisfied \\
\hline $\begin{array}{l}\text { Are you satisfied with the current salary } \\
\text { system? }\end{array}$ & $1.39 \%$ & $8.33 \%$ & $51.39 \%$ & $31.94 \%$ & $6.94 \%$ \\
\hline $\begin{array}{l}\text { Are you satisfied with the benefits provided } \\
\text { by the company? }\end{array}$ & $1.39 \%$ & $13.89 \%$ & $40.28 \%$ & $34.72 \%$ & $9.72 \%$ \\
\hline $\begin{array}{c}\text { Are you satisfied with the promotion } \\
\text { system? }\end{array}$ & $0.00 \%$ & $8.33 \%$ & $48.61 \%$ & $37.50 \%$ & $5.56 \%$ \\
\hline $\begin{array}{l}\text { Are you satisfied with the company's } \\
\text { training system? }\end{array}$ & $0.00 \%$ & $4.17 \%$ & $48.61 \%$ & $40.28 \%$ & $6.94 \%$ \\
\hline $\begin{array}{l}\text { Are you satisfied with the company's } \\
\text { corporate culture? }\end{array}$ & $1.39 \%$ & $1.39 \%$ & $41.67 \%$ & $45.83 \%$ & $9.72 \%$ \\
\hline $\begin{array}{l}\text { Are you satisfied with your communication } \\
\text { with your supervisor? }\end{array}$ & $0.00 \%$ & $9.72 \%$ & $33.33 \%$ & $47.22 \%$ & $9.72 \%$ \\
\hline
\end{tabular}

Table 2.

\begin{tabular}{|c|c|c|c|c|c|c|c|c|}
\hline Questions\Options & 1 & 2 & 3 & 4 & 5 & 6 & 7 & Average \\
\hline Competitive salary & $0.00 \%$ & $1.39 \%$ & $2.78 \%$ & $11.11 \%$ & $19.44 \%$ & $27.78 \%$ & $37.50 \%$ & 5.82 \\
\hline Good welfare & $0.00 \%$ & $1.39 \%$ & $1.39 \%$ & $13.89 \%$ & $13.89 \%$ & $31.94 \%$ & $37.50 \%$ & 5.86 \\
\hline $\begin{array}{c}\text { Medical care, unemployment, } \\
\text { industrial injury and other social } \\
\text { insurance }\end{array}$ & $1.39 \%$ & $0.00 \%$ & $2.78 \%$ & $13.89 \%$ & $16.67 \%$ & $25.00 \%$ & $40.28 \%$ & 5.81 \\
\hline Vacation benefits & $1.39 \%$ & $0.00 \%$ & $1.39 \%$ & $19.44 \%$ & $16.67 \%$ & $26.39 \%$ & $34.72 \%$ & 5.68 \\
\hline Long-term work security & $0.00 \%$ & $0.00 \%$ & $1.39 \%$ & $13.89 \%$ & $19.44 \%$ & $31.94 \%$ & $33.33 \%$ & 5.82 \\
\hline Elastic plan & $0.00 \%$ & $1.39 \%$ & $2.78 \%$ & $19.44 \%$ & $23.61 \%$ & $25.00 \%$ & $27.78 \%$ & 5.51 \\
\hline $\begin{array}{c}\text { Comfortable working } \\
\text { environment }\end{array}$ & $0.00 \%$ & $1.39 \%$ & $1.39 \%$ & $19.44 \%$ & $13.89 \%$ & $27.78 \%$ & $36.11 \%$ & 5.74 \\
\hline $\begin{array}{c}\text { Corporate culture consistent with } \\
\text { personal values }\end{array}$ & $0.00 \%$ & $0.00 \%$ & $5.56 \%$ & $18.06 \%$ & $19.44 \%$ & $23.61 \%$ & $33.33 \%$ & 5.61 \\
\hline $\begin{array}{c}\text { Appropriate and sufficient } \\
\text { authorization }\end{array}$ & $0.00 \%$ & $2.78 \%$ & $2.78 \%$ & $18.06 \%$ & $23.61 \%$ & $22.22 \%$ & $30.56 \%$ & 5.51 \\
\hline Full communication and trust & $0.00 \%$ & $1.39 \%$ & $0.00 \%$ & $15.28 \%$ & $22.22 \%$ & $23.61 \%$ & $37.50 \%$ & 5.79 \\
\hline $\begin{array}{l}\text { Space for personal development } \\
\text { and promotion }\end{array}$ & $1.39 \%$ & $0.00 \%$ & $2.78 \%$ & $15.28 \%$ & $16.67 \%$ & $25.00 \%$ & $38.89 \%$ & 5.76 \\
\hline $\begin{array}{c}\text { Work content which they are } \\
\text { interested in }\end{array}$ & $0.00 \%$ & $0.00 \%$ & $2.78 \%$ & $22.22 \%$ & $12.50 \%$ & $23.61 \%$ & $38.89 \%$ & 5.74 \\
\hline Challenging work & $2.78 \%$ & $1.39 \%$ & $2.78 \%$ & $16.67 \%$ & $30.56 \%$ & $25.00 \%$ & $20.83 \%$ & 5.29 \\
\hline Vocational training & $1.39 \%$ & $1.39 \%$ & $6.94 \%$ & $18.06 \%$ & $20.83 \%$ & $30.56 \%$ & $20.83 \%$ & 5.31 \\
\hline $\begin{array}{l}\text { Reasonable and fair assessment } \\
\text { and promotion mechanism }\end{array}$ & $1.39 \%$ & $0.00 \%$ & $5.56 \%$ & $11.11 \%$ & $19.44 \%$ & $26.39 \%$ & $36.11 \%$ & 5.71 \\
\hline
\end{tabular}

\subsubsection{Analysis of the Importance of the Incentive} Factors to Post-90s Employees

According to the survey results, good welfare, competitive salary and long-term job security are the most important incentive factors for post-90s workers. On the contrary, challenging work, vocational training and appropriate and sufficient authorization show less importance in motivating post-90s employees. The specific data are shown in Table 2.

\subsection{Existing Problems of New Generation Incentive Modes in Smes}

\subsubsection{Single Incentives and Imperfect System}

Due to their own limitations, small and medium-sized enterprises are still in the primary stage of human resource management and the means of employee incentives is relatively simple. Most small and medium-sized enterprises only pay attention to short-term salary incentives, but ignore the mental incentives. For an employee, material is the foundation as well as the guarantee of normal life. But satisfying the spiritual pursuit is the effect of long-term incentives. Using a single material incentive can only motivate employees for a short time. For different employees, especially between post-90s and post-70s, 80 employees, incentives also need to be adjusted accordingly.

\subsubsection{Imperfect Promotion System and Deficient in Career Planning}

Small and medium-sized enterprises failed to build a sound promotion system, resulting in post-90s 
employees' ambiguity in exact promotion paths, promotion conditions and skills required for the corresponding position. The direct appointment of superiors will frustrate post-90s employees' initiative for work and impact their enthusiasm for promotion. It also causes unfair emotions to spread among employees, thus forming a bad image. The imperfect promotion system, a manifestation of career planning deficiency, has no prospect for employee development and fails to give full play to the talents of employees.

\subsubsection{Less Training Opportunities and no Strong Pertinence}

Concerning the cost of enterprise, small and medium-sized enterprises rarely carries out learning and training for employees. Different from post-70s and 80s, post-90s employees possess good educational foundation, learning capability and creativity. They hope to play their own value in their work. At the same time, post-90s employees face great social pressure and fierce competition. Only by constantly improving themselves and paying more attention to development in work can they bring greater benefits to their companies. Enterprises should be prospective to see future development space of post-90s employees and give them timely training, target skills strengthening and skills upgrading, so that post-90s employees can achieve self-worth in work and bring greater value to enterprises.

\subsubsection{Poor Attractiveness of Wage Composition}

As mentioned above, the salary composition of most small and medium-sized enterprises is "base salary + performance". Year-end bonus is uncertain. According to the questionnaire facts, post-90s employees from small and medium-sized enterprises preferred the salary composition of "base salary + performance + subsidies + year-end bonus", which is sufficient to show that existing salary composition has poor attractiveness and cannot give full play to incentive effects.

\section{CONSTRUCTION OF INCENTIVE MODE FOR POST-90S EMPLOYEES IN SMES}

\subsection{Material Incentive Scheme}

\subsubsection{Establish and Perfect Salary Management System}

Post-90s employees emphasize material interests, emotional experience and self-interests. To build a sound salary management system should start from the perspective of the needs of post-90s employees instead of original needs of enterprises. We should focus on the following aspects.
The first is basic wage differentiation. Enterprises should formulate one basic wage for one job according to job analysis and job skill requirements. Meanwhile, enterprises should determine basic wage amount based on comprehensive factors such as relative value of positions, work or employee's technical level, effort degree, task difficulty, work responsibility and work environment. For key post talents, scarce post talents and technical post talents, the basic wage can be higher than the market level. For general post-90s employees, the basic wage can be consistent with the market level. ${ }^{[1]}$

The second is the close combination of performance appraisal results and performance salary. It is necessary to formulate a reasonable and perfect performance appraisal system based on job analysis. Performance appraisal should be open, fair and impartial, so that the results of each employee can be followed and justified. The performance appraisal results are applied to salary system and link to performance salary.

\subsubsection{Improve the Welfare Incentives in Many Ways}

Because of their own characteristics, post-90s employees value salary, pay attention to welfare and like the sense of ritual. Welfare is also an important point that post-90s employees are very concerned about, which is different from the post70s, 80s employees. On one hand, post-90s employees focus on holidays and tourism for their welfare requirements, thus enterprises can organize team tours regularly and handle the holiday system flexibly. On the other hand, they also value each festival relatively, so companies can send gifts on the day to let employees feel warm. In other aspects, the availability of gyms, housing offers, free afternoon tea, etc. give post-90s employees satisfaction and motivate them to work actively.

\subsection{Mental Incentive Scheme}

\subsubsection{Improving Multi-channel Promotion Mechanism}

Career management is an important path for employees' growth and development. At present, employees' career development can be achieved through multiple career paths [2]. Some large domestic enterprises have begun to set up a multi-channel promotion path for employees to choose according to their interest and suitability. This multi-channel promotion mechanism can encourage post-90s employees to learn independently and manage spontaneously, realizing the unity of post-90s employees' career development and company development, and sharing development results. To improve a multi-channel promotion mechanism needs to pay attention to the following aspects. 
The first is to establish a management and technology parallel professional channel. The management and technical personnel are separated on the promotion path, and the rank system is set to facilitate the performance appraisal and the development of promotion standards. The second is to build a horizontal development channel. After several years in the same job, employees are prone to boredom, resulting in low work efficiency. Then providing opportunities for job transfer and rotation will enable employees to improve work efficiency and eliminate fatigue when they work in other positions.

\subsubsection{Construct Training System Based on Post-90s' Career Development}

The first is to develop training plans based on the needs of post-90s employees. For example, for the newly recruited post-90s employees, the company's training goal is to teach new employees the skills and knowledge needed for the job, and detailed research should be carried out at the same time to determine what specific skills are needed in the work [3]. For employees who have been in the company for several years, training plans can be formulated according to the results of performance appraisal.

The second is post-90s staff's training options. Enterprises can provide different training methods for employees to choose and determine a training method which a majority of people can accept before training begins, so the post-90s employees can receive new knowledge in a familiar way.

\subsubsection{Improve Corporate Cultural Atmosphere}

Corporate culture is the soul of enterprises and inexhaustible motivation to promote the development of enterprises. Building a distinctive corporate culture and firmly grasping the focus of corporate culture construction are of great significance to enhance employee cohesion, centripetal force and loyalty [4]. Most managers in small and medium-sized enterprises are post-70s and post-80s whose management method for post-90s employees is relatively old, and they pay little attention to the construction of corporate culture. For modern enterprises, corporate culture is particularly important, especially in the spiritual culture. Whether the post-90 s employees fit with the enterprise in spirit has a profound impact on the enthusiasm of employees. Improving the culture of small and medium-sized enterprises is very important for the management of employees. The following aspects need to be focused on.

The first is to cultivate and advocate corporate culture that employee accept. Good corporate culture is the adhesive between enterprises and employees. It can unite employees in spirit and other aspects, produce centripetal force and cohesion, improve employee loyalty and reduce turnover rate. Small and medium-sized enterprises should integrate enterprise culture with enterprise management. They should not stay in the surface and propagandize superficially, but deepen the enterprise culture in all aspects such as system, management, employees' hearts and so on to achieve the integration of enterprise and culture, and to promote the positive progress of employees.

The second is to strengthen team building and cultivate team spirit. The post-90s employees are still lacking in team work. Although the post-90s employees do not reject team cooperation, they perform badly in the team. Enterprises can properly conduct team building to improve the tacit understanding and cohesion in teams, thereby improving the work efficiency, so that the $90 \mathrm{~s}$ employees will no longer have the feeling of "the spirit is willing, but the flesh is weak".

\section{CONCLUSION AND PROSPECT}

China's small and medium-sized enterprises occupy an important position in China's enterprises, and the research on the incentive mode of post-90s employees is a problem that managers must pay attention to. Most of the small and medium-sized enterprises lack perfect and reasonable incentives, and think little of the incentive problems of post-90s employees, resulting in a large number of post-90s employees dissatisfied with the status quo and high turnover rate. Post-90s employees are the freshest and most dynamic resources in the talent market. Frequent brain drain is detrimental to the development of enterprises, and even a major blow to the enterprises. Therefore, if SMEs want to achieve sustainable development, it will be of great significance to study how to retain, motivate and strengthen employees. At present, the incentive problems of post-90s employees receive have attracted extensive interest at home and abroad. Based on the literature, this paper studies the existing post-90s employees' incentive methods with the help of relevant concepts of incentive theory, combined with the specific situation of SMEs and construct a reasonable incentive method for post-90s employees from two directions of material incentive and promotion incentive.

Due to the limited research conditions and insufficient personal research experience and ability, there are still some unreasonable and imperfect aspects which need further improvement in the future although the research has yielded certain results. It is hoped that a reasonable and perfect scheme will be finally provided for the incentive of the post-90s employees in SMEs to achieve a win-win situation for the enterprises, employees and performance. 


\section{REFERENCES}

[1] Lian Yongsheng. Research on the Incentive Mechanism of the New Generation of Employees in C Company [D]. HeNan: Henan University Of Science And Technology, 2015

[2] Li Qianrong. Research on Motivation Factors of Knowledge Workers in the Early Stage of Career [D]. Southwest University, 2011
[3] Hu Haiyan. Research on the Cultivation of Professional Ability of New Generation Employees [D]. East China University Of Science And Technology, 2013

[4] Qu Chunlei. A Brief Analysis of the Effective Communication Skills between Business Managers and Post-80s and 90s [J]. Technology Information, 2011(9): 52. 